\title{
Educação ambiental e epistemologia: conhecimento e prática de fronteira ou uma disciplina a mais?
}

\author{
Dimas Floriani $^{1}$
}

Resumo: Este artigo pretende apresentar uma breve introdução ao problema da epistemologia e sua relação com a educação ambiental. Expõe da mesma forma alguns requisitos para a construção de uma epistemologia socioambiental, além de sugerir que, para discutir questões do desenvolvimento e do meio ambiente, são necessárias práticas apoiadas em métodos interdisciplinares, aproximando para o diálogo as ciências da vida, da natureza e da sociedade. Do conjunto dessas categorias de análise e das formas de sua implementação na pesquisa emergem questões que foram trabalhadas coletivamente no Grupo de Discussão de Pesquisas EA e Questões Epistemológicas, do V EPEA, realizado em 2009 na cidade de São Carlos, SP.

Palavras-chave: Epistemologia Ambiental, Educação Socioambiental, Interdisciplinaridade, Meio Ambiente.

Abstract: This paper presents a brief introduction to the problem of epistemology and its relation to environmental education. It also briefly presents some requirements for the construction of an environmental epistemology and suggests that, in order to discuss issues related to development and environment, there is a need for practices supported by interdisciplinary methods, bringing natural, social and life sciences together so as to promote dialogue. Based on those categories of analysis and the ways they are applied to research, the "Environmental Education and Epistemology" Research Group has worked on some issues during the V EPEA, held in 2009 in São Carlos, São Paulo.

Keywords: Environmental Epistemology, Social-Environmental Education, Interdisciplinarity, Environment.

\section{Apresentação}

Os conteúdos apresentados neste artigo refletem as práticas de discussão interativas desenvolvidas no Grupo de Discussão de Pesquisas (GDP) EA e Questões Epistemológicas no V EPEA, na UFSCar, cidade de São Carlos, SP, entre os

\footnotetext{
${ }^{1}$ Doutor em Sociologia e Professor Titular da UFPR. Líder do Grupo de Pesquisa "Epistemologia e Sociologia Ambiental" (CNPq). Coordenador do Grupo de Discussão de Pesquisas EA e Questões Epistemológicas no V EPEA, 2009. Contato: UFPR / Depto> Ciências Sociais / SCHLA, Rua General Carneiro, 460, Ed, Dom Pedro I $9^{\circ}$ andar. Curitiba-PR 80060-150 ou floriani@ufpr.br
} 
dias 30 de outubro e 2 de novembro de 2009. A organização dos conteúdos e a sua apresentação correspondem a três aspectos: no primeiro, são sistematizadas as principais questões teóricas sobre epistemologia socioambiental; no segundo, são apresentados os fundamentos da prática de pesquisa interdisciplinar em meio ambiente e desenvolvimento, nos quais se situam os principais aspectos de interesse para a educação ambiental; finalmente, no terceiro aspecto, são apresentadas questões teórico-práticas de relevância para a educação ambiental, derivadas dos questionamentos e das contribuições do coletivo presente no GDP.

O título do capítulo reflete o caráter ambíguo e polêmico da questão de uma epistemologia própria ao campo ambiental ou socioambiental. Essa questão permeou o encontro desde a conferência inaugural até os diversos GDPs do V EPEA, em especial o de EA e Epistemologia, no qual o tema de uma epistemologia ${ }^{2}$ sui generis e própria à educação ambiental refletiu diversas concepções de ciência e metodologias diferenciadas, tais como as da interdisciplinaridade e da transdisciplinaridade na abordagem da problemática socioambiental da educação. Estaríamos diante daquilo que Bourdieu consagrou com o nome campo ${ }^{3}$ ? Ou, ainda, esse debate, que está longe de finalizar, se inscreveria naquilo que alguns autores situam no espaço das chamadas ciências pós-normais ${ }^{4}$, em oposição ao que Kuhn (2000) considerava como paradigma ou ciência normal?

2 "A epistemologia ou teoria do conhecimento, é conduzida por duas questões principais: "O que é conhecimento?" e "O que podemos conhecer?". Se pensamos que podemos conhecer algo, como quase todo mundo, então surge uma terceira questão essencial: "Como conhecemos o que conhecemos?". A maioria do que já foi escrito na epistemologia através dos tempos aborda ao menos uma dessas três questões. Por exemplo, no Teeteto, Platão considera a tese de que o conhecimento é a crença verdadeira que pode ser justificada com um relato ou uma explicação. Racionalistas como Descartes e empiristas como Hume defenderam teses opostas sobre como conhecemos, e também discordaram sobre o que podemos conhecer" (GRECO, 2008, p. 16).

3 A noção de campo corresponde sociologicamente ao que Bourdieu (2004) designa como espaço social atravessado por conflitos e disputas de sentidos e interesses em torno das práticas e instituições sociais (educação, arte, ciência, etc.). No presente caso, a referência é ao subcampo socioambiental, inscrito no interior do campo científico enquanto locus estruturado de posições disputadas pelos agentes sociais que o constituem.

4 "Os novos problemas relacionados a riscos e ao meio ambiente têm aspectos comuns que os distinguem dos problemas científicos tradicionais: os fatos são incertos, os valores, controvertidos, as apostas, elevadas e as decisões, urgentes. Chamamos de ciência pósnormal a estratégia de resolução de problemas adequada a esse contexto. A função essencial de controle de qualidade e avaliação crítica não pode mais ser desempenhada por um corpo restrito de especialistas. O diálogo sobre a qualidade e a formulação de políticas devem ser estendidos a todos os afetados pela questão, que formam o que chamamos de 'comunidade ampliada dos pares"' (FUNTOWICZ; RAVETZ, 1997). 


\section{1 - Uma breve introdução ao problema da epistemologia e sua relação com a educação ambiental}

A epistemologia nos coloca frente aos processos cognitivos (biopsíquico-naturais) e socioculturais. $\mathrm{O}$ interessante aqui é indagarmos como cada uma e ao mesmo tempo algumas das ciências internalizam e constroem suas estratégias e modelos cognitivos, além de expor suas próprias compreensões sobre a relação sujeito-objeto. Possuímos nesse tema uma paisagem diversificada de concepções filosóficas sobre a história dessa relação. A história do materialismo e do idealismo nos ajuda a melhor entender esse processo.

Pode-se esboçar uma história da história da relação sujeito-objeto tanto a partir da história do sujeito-consciência como da história dos objetos, porém, sempre narrada por alguém ou por discursos. Teríamos que dar lugar aqui a dois autores que se ocupam da constituição do conhecimento na modernidade: Michel Foucault $(1967,1969)$ e Peter Burke (2003).

Desde as origens do registro da história do conhecimento humano, no Ocidente, e da problematização entre teoria e prática, as práticas materiais e representacionais expressam sistemas diferentes e complementares entre processos de racionalização e sistemas de valores (episteme $\mathrm{x}$ doxa). A episteme é sinônimo de pensamento organizado, submetido ao crivo de normas lógicas e a critérios de controle instituídos e legitimados culturalmente; doxa, por sua vez, implica a produção e uso de saberes espontâneos, opinativos e do senso comum, ligados a valores e juízos morais, embora também culturalmente chancelados. A história dessa relação também é tênue e oscila entre a reivindicação, por alguns pensadores, da primazia do conhecimento científico sobre os demais (ALTHUSSER, 1965; BOUDON, 1989; POPPER, 1975) e a coexistência de todos os conhecimentos, tendo cada um sua importância e sua razão de ser (FEYERABEND, 2003; SANTOS, 2002; STENGERS, 2002).

A epistemologia ocidental é movida pelo objetivismo; o ato de conhecer é constitutivo do objeto de conhecimento, em oposição às epistemologias não ocidentais ou indígenas, para as quais conhecer bem alguma coisa é ser capaz de atribuir o máximo de intencionalidade ao que se está conhecendo (VIVEIROS DE CASTRO, 2002).

A modernidade ocidental operou com a radicalidade dessa separação representacional do mundo, instituindo o projeto científico como sua forma preponderante, cuja lógica está assentada na disjunção, em detrimento da conjunção. As ciências caminham assim, em direção às tecnociências, 
conhecimento aplicado, no mercado globalizado, incorporando assimetrias nas formas de produção, apropriação e controle geopolítico de seus resultados. A crítica que emerge desse modelo hegemônico (do ser e do pensar) é política, cultural, filosófica, epistemológica, enfim, civilizatória.

Por sua vez, a epistemologia socioambiental emerge das condições de produção e de acesso ao conhecimento, em territórios de fronteira (ciências pósnormais que emergem do diálogo entre conhecimentos científicos e não científicos ou culturais), demarcados pela existência de objetos complexos, que exigem uma atitude deliberada na formulação e no uso desses conhecimentos para pensar e agir nos domínios das relações que se estabelecem entre sociedade e natureza.

Encontramo-nos em situação de trânsito epistemológico quando pensamos o significado dessa crise. Para nomear a ação dessa ressignificação na ocupação desse espaço vazio, emergem intenções plurais, híbridas ou mestiças, assentadas em alguns novos sistemas de pensamento que expõem os atoressujeitos culturais a diferentes formas do pensar-agir: diferentes teorias se associam a esse novo campo, atravessado por diversos dispositivos cognitivos, políticos, culturais, teórico-metodológicos, educacionais, tecnológicos, etc., no qual se inserem também as teorias e práticas educacionais, convidadas a repensar seus instrumentos cognitivo-valorativos e sua nova relação com os sistemas de práticas e os sistemas de objetos.

Pode ocorrer, assim, uma subversão de racionalidades, alterando ou relativizando a relação entre meios e fins, própria ou constitutiva da racionalidade instrumental, orientada pelas ideias de progresso e de apropriação da natureza como insumo ou recurso natural voltado para o crescimento econômico.

O contexto da pesquisa ganha sua condição de indutor do processo constitutivo do conhecimento e não é mais considerado como externalidade.

Uma nova epistemologia, inspirada pela crítica emergente que deve ser múltipla ou plural, que contemple o diverso epistemológico do dissenso, pode ser a expressão de diversas vias, de acordo com o princípio de uma epistemologia da diversidade (FLORIANI, 2009).

Se utilizarmos, por exemplo, os enunciados do pensamento complexo em relação ao conhecimento científico, este progredirá mais pela eliminação dos erros do que pelo aumento de verdades; o processo do conhecimento ocorrerá juntamente com o progresso da ignorância e as regras do jogo entre verdade e erro serão mais significativas do que a verdade científica contida nas teorias. 
Surgem outras lógicas para reordenar sentidos (como é o caso das lógicas paraconsistentes).

Várias teorias e sistemas de pensamento coexistem/concorrem/ disputam diferenças e complementaridades entre si: as diferentes concepções do construtivismo social (HANNIGAN, 1995; LATOUR, 2004), a teoria da coevolução (REDCLIFT; WOODGATE, 1998), as novas ontologias sobre o social (CASTORIADIS, 1980; GIDDENS, 1989), o pensamento complexo de Morin (1998), a autopoiésis da Escola de Santiago (MATURANA; VARELA, 2007), as teorias do caos, da irreversibilidade em Prigogine (1980), a teoria da auto-organização de Atlan (1992), a teoria da racionalidade ambiental de Leff (2009), o holismo de Capra (2005), entre diversas outras teorias e autores, além das releituras de filósofos e teóricos das ciências humanas, naturais e da vida que repensam seus objetos teóricos à luz dos problemas emergentes de fronteiras entre os diversos tipos de conhecimento científico e as etnociências.

\section{2 - Requisitos para a construção de uma epistemologia socioambiental ${ }^{5}$}

Uma epistemologia emergente deve tratar das condições de produção e de acesso ao conhecimento, não desvinculadas dos mecanismos de intervenção, do fazer saber e do saber fazer.

Uma epistemologia socioambiental emergente deve saber integrar os fundamentos de uma filosofia do conhecimento, culturalmente condicionado e historicamente estabelecido, que leve em conta as trajetórias constitutivas de uma história da ciência, mas também dos saberes culturalmente enraizados e reinventados pela diversidade do pensamento vivo e corporificado em práticas, saberes críticos e tecnologias inventadas pela engenhosidade humana, em diálogo tenso, contraditório, criativo e crítico sobre os processos de interação das sociedades com a natureza.

Uma epistemologia socioambiental deve inscrever-se na confluência dos paradigmas em transição, refutando as simetrias unidimensionais de apenas uma matriz de pensamento e de valores; deve privilegiar o diálogo com a diferença, os espaços garantidos pelo pensamento complexo e híbrido e pela pluralidade diferenciadora. Mas deve também saber reconhecer as ingenuidades discursivas e

\footnotetext{
${ }^{5}$ Esta seção apoia-se principalmente em outros textos do autor (FLORIANI, 2004, 2005,
} 2007; FLORIANI; KNECHTEL, 2003). 
a ideologização fácil, tanto afirmativas como negativas, simplificadoras e hegemônicas.

Uma epistemologia socioambiental emergente é aquela que redefine a história do conhecimento pela radicalidade das releituras dos processos de vida, pela natureza e significado da vida, pela semântica e polifonia dos sentidos culturais, em conjunção com a diversidade dos ecossistemas, a "fisicalidade" do mundo e sua permanente mutação e negação, integrando-se a uma nova filosofia dos processos culturais, cognitivos, tecnológicos, imaginativos, éticos, estéticos e utópicos por meio de novas alianças afirmativas entre os tempos do espírito, da matéria e dos valores que cimentam a viabilidade da vida, das emoções, da alteridade, do ser acontecendo. Uma nova epistemologia dessa ordem obriga a construir os sentidos da vida e do mundo pela educação (ou reeducação) dos sentidos.

Uma epistemologia socioambiental não pode operar sem uma teoria que englobe o entendimento da linguagem, do sujeito ${ }^{6}$, do evento histórico-cultural, como um campo de disputas pela construção de sentidos práticos e simbólicos, o que implica interpretar o devir, o que acontece e o acontecido nas interfaces sociedade-natureza.

\section{3 - Desenvolvimento e meio ambiente pensados interdisciplinarmente ${ }^{7}$}

Pensar o desenvolvimento humano levando em conta suas implicações para o domínio do "meio ambiente" acarreta a necessidade da interdisciplinaridade.

O fato de se falar de "meio ambiente" e não de ecossistemas ou de sistemas físicos ou biológicos implica a inclusão do ser humano, individualmente ou coletivamente, como ocupante e utilizador de um espaço e do conjunto de objetos e seres bióticos e abióticos aí compreendidos. Isso significa dizer que o meio ambiente designa o mundo físico e biótico sob a ótica das relações com os seres humanos.

A noção de meio ambiente é multicêntrica, aplicando-se, de acordo com as perspectivas adotadas, a indivíduos, grupos, organismos e populações de seres vivos. De uma representação a outra, se produzem deslocamentos de tal maneira

${ }^{6}$ Para Badiou (1994, p. 45), "um sujeito é primeiramente aquilo que fixa um evento indecidível, porque assume o risco de decidi-lo".

7 Algumas das ideias centrais desta seção estão fortemente apoiadas em Floriani (2004, 2005) e Raynaut (2002). 
que o que era o objeto central da definição se torna um elemento a mais em outro contexto. Além disso, os processos ambientais se desenvolvem por meio de múltiplas escalas de espaço e tempo e mobilizam uma enorme diversidade de níveis de organização. Da molécula até o ecossistema, do local até a paisagem em sua globalidade, muitos são os níveis de organização a serem levados em conta na elaboração de um modelo explicativo referente a uma situação ambiental.

O ritmo das dinâmicas observadas muda segundo as escalas de observação adotadas, passando do instantâneo ao tempo geológico. Isso se torna visível quando se trata dos sistemas físicos e biológicos. Verifica-se, também, no que diz respeito à vertente humana da relação, segundo o ponto de referência, o indivíduo, a comunidade local, a nação, os bilhões de seres humanos que povoam a Terra.

O significado do termo "meio ambiente" e os fenômenos a serem analisados mudam ao se passar das condições de vida ao alcance de uma pessoa e ao seu entorno imediato para as condições do planeta e as mudanças globais e de longo prazo. Não se trata de simples diferenças formais, uma vez que para cada nível de análise aparecem propriedades que não existiam em um nível inferior. Uma célula não é simplesmente a soma de moléculas; uma floresta difere da justaposição de árvores. Descrever e analisar essa realidade complexa implica a intervenção de diversas disciplinas atuando em um conjunto de níveis de apreensão e utilizando diferentes instrumentos teóricos e conceituais (RAYNAUT, 2002).

Quando se consideram não apenas as consequências dos processos ambientais sobre as sociedades humanas mas também a necessidade de incorporar as dimensões ambientais na formulação das políticas de desenvolvimento - ajustando-se objetivos econômicos, sanitários, sociais e éticos com a preservação/conservação da natureza, a exigência da interdisciplinaridade se faz ainda mais presente, abrindo-se para um espaço mais amplo.

A colaboração entre ciências físico-naturais, disciplinas técnicas e ciências sociais se torna absolutamente necessária, uma vez que se trata de analisar não só a complexidade dos sistemas físico-naturais mas igualmente as interações com a sociedade.

Essa construção contempla um modelo analítico no qual se encontram dois "campos" de realidade diferentes e, ao mesmo tempo, estreitamente conectados:

O campo das relações físicas e biológicas: compreende o conjunto das relações biológicas e físico-químicas tecidas no interior dos grandes domínios da 
organização biológica, como a atmosfera, pedosfera, hidrosfera e geosfera. Essa rede de relações forma um sistema, subdividindo-se em muitos sistemas articulados em diferentes escalas. Essa rede inclui o homem, tomado individualmente ou reunido em populações - como organismo vivo, agente e objeto de interações biológicas e físico-químicas. Inclui também uma parte fortemente artificializada - a ponto de ser, como a cidade, um produto direto da ação humana (um artefato) -, mas que não deixa de permanecer submetida a processos da mesma ordem dos meios físicos e biológicos.

O campo das relações não materiais: compreende o conjunto de processos cuja articulação participa da organização, da reprodução e da transformação das representações mentais do mundo e dos modos de estruturação das relações sociais.

Nesse tocante, os fatos ou fenômenos que o olhar científico busca descobrir, identificar e compreender remetem a processos de produção, de circulação e de transmissão do sentido, tanto do ponto de vista da cultura coletiva (representações, valores, normas) como do ponto de vista dos intercâmbios envolvendo atores sociais. Esses processos desempenham um papel determinante na história de qualquer sociedade e se mantêm, em grande medida, autônomos em relação às determinações biológicas e físico-químicas.

Nenhuma sociedade poderia existir sem uma base material, como os próprios corpos dos indivíduos que a compõem e os bens e os objetos cuja produção, circulação e consumo permitem a reprodução social e os artefatos e interações biofísicas envolvidos na fabricação desses bens e objetos.

Essa base material faz parte integrante do estudo do sistema das relações não materiais quando, e unicamente, contribui para produzir ou transformar as relações sociais e os quadros de representação.

Por exemplo, um evento biológico tal como a epidemia da aids pode exercer uma maior influência sobre a evolução nas relações de gênero.

Outro exemplo: as novas técnicas de transplante de órgãos ou as biotecnologias provocaram mudanças profundas na definição de morte e vida, promovendo questões éticas nunca enfrentadas.

No entanto, por mais importante que possa revelar-se a influência dos fatos materiais sobre a dinâmica das ideias, aqueles nunca as determinam diretamente. Os fatos materiais são sempre interpretados em função de categorias de pensamento - e/ou relações de poder - preexistentes e que fornecem o quadro a partir do qual novos ajustes serão feitos. 
A questão ambiental, por si mesma, é a manifestação de uma tomada de consciência da capacidade do ser humano de modificar a natureza, às vezes danificando e destruindo, mas também manipulando e moldando até dar nascimento a uma "Segunda Natureza", conforme designados desde a antiguidade os espaços transformados pelas atividades humanas (RAYNAUT, 2002).

As ciências sociais devem reconhecer a natureza profundamente ambivalente da pessoa humana e das sociedades - sua dupla natureza -, ao mesmo tempo essencialmente "ideacional" ou imaterial e profundamente enraizada na matéria, o que Godelier (1984) chama de "a parte não social do social".

Por outro lado, as ciências físicas e naturais devem admitir que as produções da mente humana - representações, símbolos, saberes, valores - não são meras fantasias que vêm enfeitar ou mascarar uma realidade mais essencial, que seria a realidade da matéria. Essas ciências devem também aceitar que as dimensões do social (econômico-tecnológico), do cultural, do natural (biofísicoquímico), do biopsíquico e outras fazem parte integrante da realidade e desempenham um papel condicionante, tanto na história das sociedades como na dos ecossistemas que estudam.

Para alcançar a colaboração no estudo dos problemas ambientais, as disciplinas naturais e sociais devem conciliar duas exigências:

a) produzir um conhecimento voltado para objetos coerentes com seus conceitos e seus métodos. Em outras palavras, um antropólogo não deve estudar a dinâmica dos ecossistemas e um ecólogo não deve analisar a elaboração das representações;

b) reconhecer o caráter fundamentalmente ambivalente dos fatos sobre os quais essas disciplinas trabalham - ao mesmo tempo materiais e sociais -, o que possibilita tornar igualmente pertinentes os diferentes saberes produzidos sobre um mesmo objeto (RAYNAUT, 2002).

\section{4 - Problemas que emergem dos pontos anteriores, construídos no GDP EA e Questões Epistemológicas, do V EPEA}

4.1. Como produzir conhecimentos com base nesses fundamentos? Que metodologias de confluência desses conhecimentos e saberes podem induzir a outros procedimentos e instrumentos de pesquisa? 
4.2. Os processos interdisciplinares parecem já resultar de experiências diversas e em andamento, em processo de institucionalização, embora objeto de disputas, controvérsias e conflitos os mais diversos (de poder entre o instituído e o instituinte). Porém, o pressuposto básico da interdisciplinaridade nos estudos socioambientais é coletivo, de diálogo intersubjetivo entre as diversas disciplinas em presença. Uma boa interdisciplinaridade é feita a partir de uma boa disciplinaridade.

4.3. A transdisciplinaridade parece ser objeto de maior controvérsia e desafio, uma vez que desloca as fronteiras de suas práticas, nos espaços das ciências, das etnociências e dos demais saberes culturais.

4.4. A pergunta se é relevante ou não a EA ter uma epistemologia própria pode ser relativizada, pois não se trata de decretar um monopólio próprio, dado que a educação é um espaço de confluência e mestiçagem de conhecimentos, indo buscar nessas interseções um diálogo com o seu campo em construção.

4.5. Novas atitudes se fazem necessárias para se superar o monopólio epistemológico na EA, pelas razões expostas, embora incontáveis obstáculos persistam no interior das disciplinas, nos diversos campos do conhecimento. Trata-se de desenvolver novas culturas epistemológicas, sem a pretensão de criar um novo paradigma hegemônico.

4.6. A educação está convidada a rever seus pressupostos, partindo dessas novas atitudes e concepções epistemológicas.

4.7. Não ter a pretensão de separar o debate epistemológico das teorias e práticas da EA em construção, pois, como esta também é plural, cada um dos GDPs deve internalizar esse processo e intercambiar os resultados com os demais, a fim de obter contribuições renovadas para si e para os demais grupos em interação.

\section{Referências}

ALTHUSSER, Louis. Pour Marx. Paris: Maspero, 1965.

ATLAN, Henri. Entre o cristal e a fumaça: ensaio sobre a organização do ser vivo. Rio de Janeiro: Jorge Zahar, 1992.

BADIOU, Alain. Para uma nova teoria do sujeito. Rio de Janeiro: Relume Dumará, 1994. 
BOUDON, Raymond. A Ideologia, ou a origem das idéias recebidas. São Paulo: Ática, 1989.

BOURDIEU, Pierre. Os usos sociais da ciência: por uma sociologia do campo científico. São Paulo: UNESP, 2004.

BURKE, Peter. Uma história social do conhecimento: de Gutenberg a Diderot. Rio de Janeiro: Jorge Zahar, 2003.

CAPRA, Fritjof. As conexões ocultas. São Paulo: Cultrix, 2005.

CASTORIADIS, Cornelius. A instituição imaginária da sociedade. Rio de Janeiro: Paz e Terra, 1980.

FEYERABEND, Paul. Tratado contra el método. Madrid: Tecnos, 2003.

FLORIANI, Dimas. Disciplinaridade e construção interdisciplinar do saber ambiental. Desenvolvimento e Meio Ambiente, Curitiba, n. 10, p. 33-37, jul./dez. 2004.

. Conhecimento, meio ambiente e globalização. Curitiba: Juruá; PNUMA, 2005.

. Pensamento complexo, interdisciplinaridade e Educação Ambiental: bases para uma epistemologia socioambiental emergente. In: Perspectivas da Educaşão Ambiental na Região ibero-americana, p.497-511. Rio de Janeiro: Associação Projeto Roda Viva, 2007.

. Por uma epistemologia da diversidade. In: NAVAL, Liliana Pena; PARENTE, Temis Gomes (Org.). Impactos socioambientais: o desafio da construção de hidrelétricas. Goiânia: Cânone, 2009. p. 11-30.

FLORIANI, Dimas; KNECHTEL, Maria do Rosário. Educação Ambiental: epistemologia e metodologias. Curitiba: Vicentina, 2003.

FOUCAULT, Michel. Les mots et les choses. Paris: Gallimard, 1967. . L'archéologie du savoir. Paris: Gallimard, 1969.

FUNTOWICZ, Sílvio; RAVETZ, Jerry. Ciência pós-normal e comunidades ampliadas de pares face aos desafios ambientais. História, Ciências, Saúde, Rio de Janeiro, v. 4, n. 2, out. 1997. Disponível em: <http://www.scielo.br/scielo.php?script=sci_arttext\&pid $=$ S0104-59701997000200002\&lng=pt\&nrm=iso $>$.

GIDDENS, Anthony. A constituição da sociedade. São Paulo: Martins Fontes, 1989.

GODELIER, Maurice. L'idéel et le materiel. Pensée, economies, sociétés. Paris: Fayard, 1984.

GRECO, John. Introdução - O que é epistemologia? In: GRECO, John; SOSA, Ernest (Org.). Compêndio de Epistemologia. São Paulo: Loyola, 2008.

HANNIGAN, John. Environmental Sociology. A social constructionist perspective. London; New York: Routledge, 1995.

KUHN, Thomas S. A estrutura das revoluções científicas. 5. ed. São Paulo: Perspectiva, 2000.

LATOUR, Bruno. Politicas da natureza. Como fazer ciência na democracia. São Paulo: EDUSC, 2004. 
LEFF, Enrique. Ecologia, capital e cultura. A territorialização da racionalidade ambiental. Petrópolis: Vozes, 2009.

MATURANA, Humberto; VARELA, Francisco. El árbol del conocimiento. Santiago de Chile: Universitaria, 2007.

MORIN, Edgar. Introducción al pensamiento complejo. Barcelona: Gedisa, 1998.

POPPER, Karl. Conbecimento objetivo. Belo Horizonte: Itatiaia, 1975.

PRIGOGINE, Ilya; STENGERS, Isabelle. A nova aliança: metamorfoses da ciência. Brasília: EdUnB, 1980.

RAYNAUT, Claude (Org.). Desenvolvimento e Meio Ambiente: em busca da interdisciplinaridade. Curitiba: EDUFPR, 2002.

REDCLIFT, Robert; WOODGATE, Robert. De una sociología de la naturaleza a una sociología ambiental: más allá de la construcción social. Madri: RIS, 1998.

SANTOS, Boaventura de Sousa. Um discurso sobre as ciências. São Paulo: Cortez, 2002.

STENGERS, Isabelle. A invenção das ciências modernas. São Paulo: 34, 2002.

VIVEIROS DE CASTRO, Eduardo. A inconstância da alma selvagem e outros ensaios de antropologia. São Paulo: Cosac \& Naify, 2002.

Artigo: recebido em 28/11/2009 - aprovado em 25/12/2009 